\title{
Recycling thoracic arteries for redo coronary artery bypass grafting: Long-term follow-up
}

\author{
Marco Agrifoglio, MD, PhD, ${ }^{a}$ Fabio Barili, $\mathrm{MD},{ }^{a}$ Alessandro Parolari, MD, PhD, ${ }^{a}$ Eleonora Penza, $\mathrm{MD},{ }^{a}$ \\ Matteo Trezzi, MD, ${ }^{a}$ Gianluca Polvani, MD, ${ }^{a}$ Carlo Antona, MD, ${ }^{\text {b }}$ Francesco Alamanni, MD, ${ }^{a}$, and Paolo Biglioli, MD, ${ }^{a}$ \\ Milan, Italy
}

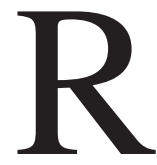

edo coronary artery bypass graft (redo CABG) procedures are a surgical challenge, especially when one or both internal thoracic arteries (ITAs) have been previously harvested. The lack of available ITA grafts at reoperation might jeopardize the long-term outcomes, because pedicle ITAs have shown longer patency than have other grafts. ${ }^{1,2}$

Early and midterm results after recycling of ITA grafts in coronary reoperations were demonstrated to be satisfactory. ${ }^{3-5} \mathrm{We}$ report clinical and angiographic long-term follow-up of this procedure.

\section{Patients and Methods}

From January 1990 to December 2005, 9 patients (7 men and 2 women) underwent redo $\mathrm{CABG}$, recycling the previously implanted ITAs. Patients were evaluated with regard to clinical, echocardiographic, and angiographic findings. They were prospectively followed up by direct visit, echocardiography, and stress test (Table 1). Between June 2006 and December 2006, a coronary angiographic follow-up was performed in all survivors (8 patients). Outcome variables included perioperative (30-day) mortality and morbidity, long-term survival, and ITA graft patency.

\section{Results}

The mean age of the population was $59.3 \pm 13.3$ years (range $38-76$ years). The preoperative transthoracic echocardiographic ejection fraction was $50.2 \% \pm 8.1 \%$. Preoperative coronary angiography excluded proximal stenoses of the ITA grafts that were recycled as pedicle grafts.

The mean interval between operations was $27.7 \pm 42.3$ months (range 1-132 months). Five patients underwent early reoperation ( $<6$ months) for stenosis at the anastomotic site. The remaining 4 patients had late reoperation owing to progression of native coronary disease.

From the Department of Cardiovascular Surgery, Centro Cardiologico Monzino, University of Milan, ${ }^{\mathrm{a}}$ and the Division of Cardiovascular Surgery, L. Sacco Hospital, Milan, Italy. ${ }^{\mathrm{b}}$

Received for publication Jan 23, 2007; accepted for publication Feb 23, 2007.

Address for reprints: Fabio Barili, MD, Department of Cardiovascular Surgery - University of Milan, Centro Cardiologico Monzino IRCCS, Via Parea 4, 20138 Milan, Italy (E-mail address: fabarili@libero.it; fabio.barili@unimi.it).

J Thorac Cardiovasc Surg 2007;134:233-5

$0022-5223 / \$ 32.00$

Copyright $\odot 2007$ by The American Association for Thoracic Surgery doi:10.1016/j.jtcvs.2007.02.025
The operation was performed on pump during cardioplegic arrest. The recycled grafts included 8 left and 2 right ITAs. One patient had both ITAs recycled. In 7 cases the left ITA had been previously anastomosed to the left anterior descending artery (LAD). In patient 3, it was transposed from an obtuse marginal branch to the LAD and the right gastroepiploic artery was anastomosed to the obtuse marginal branch. One young patient (No. 2) required the interposition of a short segment of saphenous vein between the left pedicle ITA and target LAD. The recycled right ITA was used to anastomose the right coronary artery distal to the previous anastomosis.

There were no operative or perioperative (30-day) deaths. The postoperative course was uneventful. Cumulative follow-up time was 1016.0 patient-months and was $100 \%$ complete. Complete follow-up ranged from 48 to 192 months (mean $112.8 \pm 17.6$ months, median 113 months).

At follow-up, 1 patient died of noncardiac causes 78 months after reoperation. The Kaplan-Meier overall survival estimate at 15 years was $83.3 \% \pm 15.2 \%$. The actuarial freedom from heartrelated mortality was $100 \%$.

There were 2 coronary angioplasty procedures at follow-up. Patient 2 underwent percutaneous transluminal coronary angioplasty and stenting on the anastomosis that was constructed to

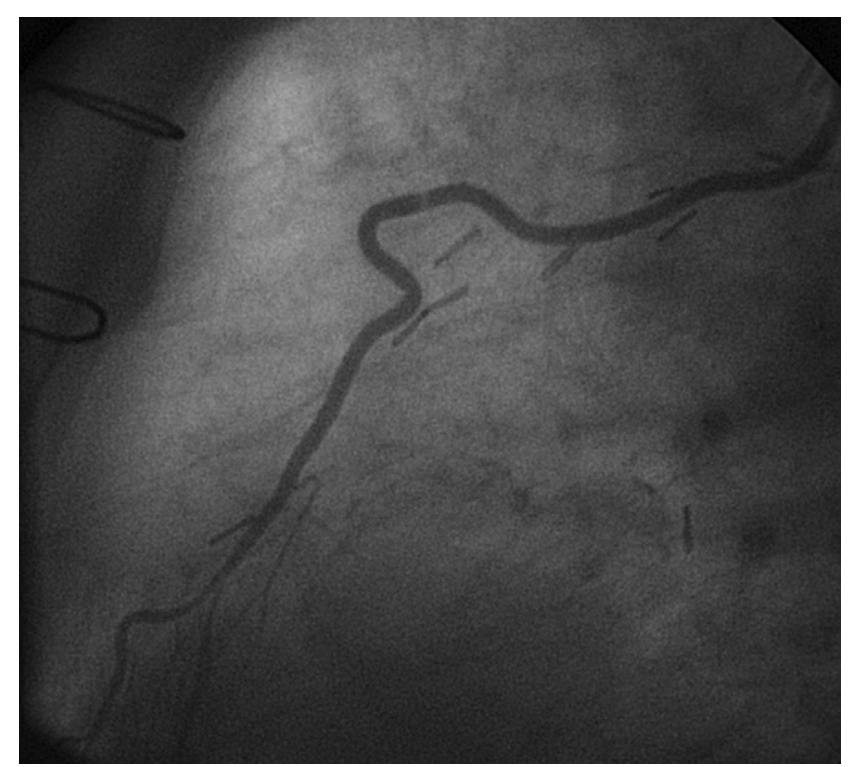

Figure 1. Long-term angiographic follow-up of a patient who underwent redo coronary artery bypass grafting. The angiogram documented the patency of the recycled left ITA to LAD. 
TABLE 1. Operative data and follow-up of patients

\begin{tabular}{|c|c|c|c|c|c|c|c|}
\hline $\begin{array}{l}\text { Pt } \\
\text { No. }\end{array}$ & $\begin{array}{c}\text { Age } \\
\text { (y) }\end{array}$ & Previous operation & $\begin{array}{c}\text { Interval } \\
\text { between } \\
\text { operations } \\
\text { (mo) }\end{array}$ & $\begin{array}{c}\text { Location and extent } \\
\text { of stenosis }\end{array}$ & Recycled ITA & Reoperation & Follow-up (mo) \\
\hline 1 & 38 & $\begin{array}{l}\text { AVR (Sorin 23) and } \\
\text { LMC plasty } \\
\text { (Takayasu } \\
\text { arteritis); } 3 \text { y } \\
\text { later, RITA to } \\
\text { RCA }\end{array}$ & 1 & $\begin{array}{l}\text { RITA to RCA } \\
\text { (distal } \\
\text { anastomosis, } \\
90 \% \text { ) }\end{array}$ & RITA & RITA to RCA & 192 \\
\hline 2 & 40 & $\begin{array}{l}\text { LITA to LAD; RITA } \\
\text { to PDA; SVG to } \\
\text { OM }\end{array}$ & 5 & $\begin{array}{l}\text { LITA to LAD (distal } \\
\text { anastomosis } \\
\text { 99\%); RITA to } \\
\text { PDA (distal } \\
\text { anastomosis } \\
80 \% \text { ); SVG to } \\
\text { OM (proximal } \\
\text { anastomosis } \\
80 \% \text { ) }\end{array}$ & LITA, RITA & $\begin{array}{l}\text { LITA to LAD (SVG } \\
\text { interposed); } \\
\text { RITA to RCA; } \\
\text { SVG to PDA; } \\
\text { new proximal } \\
\text { anastomosis of } \\
\text { SVG to OM }\end{array}$ & $\begin{array}{l}\text { 171; PTCA on LITA } \\
\text { to LAD with } \\
\text { interposed SVG } \\
\text { after } 123 \text { mo }\end{array}$ \\
\hline 3 & 65 & $\begin{array}{l}\text { LITA to OM; SVG } \\
\text { to PDA and PLA }\end{array}$ & 35 & $\begin{array}{l}\text { LAD }(75 \%) \text {, LITA to } \\
\text { OM (distal } \\
\text { anastomosis } \\
\text { 99\%); SVG to } \\
\text { PDA and PLA } \\
(70 \%)\end{array}$ & LITA & $\begin{array}{l}\text { LITA to LAD; } \\
\text { RGEA to OM; } \\
\text { sequential SVG } \\
\text { to PDA and } \\
\text { PLA }\end{array}$ & 148 \\
\hline 4 & 56 & $\begin{array}{l}\text { LITA to LAD; SVG } \\
\text { to OM }\end{array}$ & 15 & $\begin{array}{l}\text { LITA to LAD (distal } \\
\text { anastomosis, } \\
90 \%) 1 \text { st DIAG } \\
(70 \%) ; \text { PDA } \\
(70 \%)\end{array}$ & LITA & $\begin{array}{l}\text { LITA to LAD; } \\
\text { RGEA to PDA; } \\
\text { SVG to } 1 \text { st } \\
\text { DIAG }\end{array}$ & 142 \\
\hline 8 & 62 & LITA to LAD & 5 & LITA to LAD & LITA & LITA to LAD & 59 \\
\hline 9 & 75 & LITA to LAD & 4 & LITA to LAD & LITA & $\begin{array}{l}\text { LITA to LAD; SVG } \\
\text { to PDA }\end{array}$ & $\begin{array}{l}\text { 48; (PTCA on CFX } \\
\text { after } 19 \mathrm{mo} \text { ) }\end{array}$ \\
\hline
\end{tabular}

AVR, Aortic valve replacement; CFX, circumflex artery; DIAG, diagonal artery; ITA, internal thoracic artery; $L I T A$, left internal thoracic artery; $L M C$, left main coronary artery; $L A D$, left anterior descending artery; $O M$, obtuse marginal artery; $P D A$, posterior descending artery; PLA, posterolateral artery; PTCA, percutaneous transluminal coronary angioplasty; $R C A$, right coronary artery; RGEA, right gastroepiploic artery; RITA, right internal thoracic artery; SVG, saphenous vein graft.

elongate the left ITA with an interposed saphenous vein graft, and patient 8 underwent angioplasty on the circumflex artery for the progression of coronary artery disease. The other patients had no recurrent angina and no abnormalities on stress testing. At longterm follow-up, coronary angiography showed patency of the recycled ITAs in all cases (Figure 1). Actuarial freedom from restenosis of recycled ITA graft at 15 years was $75.0 \% \pm 21.7 \%$.

\section{Discussion}

ITA is the graft of choice in terms of patency and durability, as it has been proven to improve long-term outcomes. ${ }^{1,2}$ These benefits could be helpful even in patients who undergo redo surgical myocardial revascularization, above all in younger patients who have a longer life expectancy.

The recycling of ITA grafts can be performed with excellent clinical results, although it introduces further technical difficulties to a challenging operation. ${ }^{3-5}$ In this limited experience, we reused previously placed ITA grafts with no perioperative deaths or complications. The long-term clinical and angiographic follow-up demonstrated that recycled ITAs maintain a high rate of patency even at long-term follow-up. Only 1 patient needed angioplasty of the graft, but the restenosis was located 
at the anastomosis between the ITA and the saphenous vein elongation.

The recycling of ITA grafts can be performed in only a selected redo $\mathrm{CABG}$ population, ${ }^{3}$ when the ITA is patent but stenotic in the perianastomotic area, when there is a stenosis in the coronary artery distal to the anastomosis, and when an interventional cardiologic approach is not feasible. Preoperative selective angiography of the used ITA is helpful to exclude proximal stenosis, to locate its relationship, and to provide anatomic details that may suggest this possible alternative approach during redo $\mathrm{CABG}$ surgery.

In conclusion, our limited experience confirmed that the recycling of ITA grafts in redo CABG can produce satisfactory outcomes in selected patients even at long-term follow-up.

\section{References}

1. Burfeind WR Jr, Glower DD, Wechsler AS, Tuttle RH, Shaw LK, Harrel FE Jr, et al. Single versus multiple internal mammary artery grafting for coronary artery bypass: 15 year follow-up of a clinical practice trial. Circulation. 2004;110(Suppl):II27-35.

2. Cameron A, Davis KB, Green G, Schaff HV. Coronary bypass surgery with internal-thoracic artery grafts: effects on survival over a 15 -year period. N Engl J Med. 1996;334:216-9.

3. Noyez L, Lacquet LK. Recycling of the internal mammary artery in coronary reoperation. Ann Thorac Surg. 1993;55:597-9.

4. Antona C, Parolari A, Zanobini M, Arena V, Biglioli P. Midterm angiographic study of five recycled mammary arteries during four coronary redos. Ann Thorac Surg. 1996;61:702-5.

5. Noirhomme PH, Underwood MJ, El Khoury GA, Glineur D, Elias B, d'Udekem Y, et al. Recycling of arterial grafts during reoperative coronary artery operations. Ann Thorac Surg. 1999;67:641-4.

\title{
Complete vascular ring presenting in adulthood: An unusual management dilemma
}

\author{
Edward J. Hickey, MD, Aftab Khan, MRCS, David Anderson, FRCS, and Loic Lang-Lazdunski, FRCS, London, United \\ Kingdom
}

\section{Clinical Summary}

Patient 1. An otherwise fit 47-year-old woman presented with progressive dyspnea and wheeze on minimal exertion over several years. After a negligible response to bronchodilators, bronchoscopy demonstrated extrinsic compression causing midtracheal collapse. A computed tomographic (CT) scan indicated a right-sided aortic arch with a Kommerell diverticulum and a retroesophageal left subclavian artery (Figure 1). She underwent a left posterior lateral thoracotomy through the fifth intercostal space. The ligamentum arteriosum (completing the type 3 ring) appeared to be the principal cause of tracheal compromise and was divided to achieve complete decompression. Recovery was uneventful, and she is symptom-free 12 months later.

Patient 2. A 37-year-old female nonsmoker described limited exercise tolerance and exertional wheeze since childhood. Medical attention was sought only after significant symptom exacerbation during pregnancy. Physical examination was unremarkable, but the flow-volume loop suggested large airway obstruction. Flexible bronchoscopy revealed erythema and extrinsic compression imme-

From the Department of Thoracic Surgery, Guy's Hospital, King's College London, London, United Kingdom.

Received for publication Jan 3, 2007; accepted for publication Jan 31, 2007.

Address for reprints: Loic Lang-Lazdunski, MD, PhD, FRCS, Department of Thoracic Surgery, Guy's Hospital, King's College Hospital, St Thomas St, London SE1 9RT, United Kingdom (E-mail: loic.lang-lazdunski@ gstt.nhs.uk).

J Thorac Cardiovasc Surg 2007;134:235-6

$0022-5223 / \$ 32.00$

Copyright $\odot 2007$ by The American Association for Thoracic Surgery

doi:10.1016/j.jtcvs.2007.01.083 diately proximal to the carina in the anteroposterior plane. In addition, the origin of the right upper lobe bronchus arose directly from the carina. CT suggested these bronchoscopic findings to be attributable to a right aortic arch with an aberrant retroesophageal left subclavian artery arising from a Kommerell diverticulum. A decision was made to intervene surgically. At the fourth-space left thoracotomy, the complete vascular ring (type 3 ) was confirmed by the presence of the left ductal remnant, which was divided to allow distraction of the diverticulum away from the esophagus. Despite initial improvement, she relapsed 5 years later. A 3-dimensional $\mathrm{CT}$ reconstruction demonstrated the diverticulum compressing the trachea posteriorly. Right thoracotomy was performed to approach the aberrant left subclavian artery, the origin of which was divided and oversewn. The Kommerell diverticulum was then resected, and primary repair of the aorta was undertaken. Tracheal decompression was satisfactory, and the patient is symptom-free 12 months later.

\section{Discussion}

The right aortic arch can form a complete vascular ring through the presence of a ligamentum arteriosum (or persistent duct). In these circumstances, tracheoesophageal compression might typically occur from the embarrassment of either the ligamentum or a Kommerell diverticulum, an aortic pouch from which the aberrant subclavian artery arises. The anomaly typically becomes evident in infancy and requires, at minimum, the surgical release of the ligamentum. Recurrence occurs in a small proportion of cases and has been attributed to aneurysmal dilatation of the Kommerell diverticula, which usually require subsequent resection. ${ }^{1}$

Primary presentations in adulthood are extremely unusual but might masquerade as chronic asthma ${ }^{2}$ until identification, occasionally as late as the seventh decade. ${ }^{3}$ This report highlights 2 